\title{
Polyethylene Glycol-Surfactant for Lavage Lung Injury in Rats
}

\author{
WALTER DEHORITY, KAREN W. LU, JOHN CLEMENTS, JON GOERKE, \\ JEAN-FRANCOIS PITTET, LENNELL ALLEN, AND H. WILLIAM TAEUSCH \\ Department of Pediatrics [W.D., K.W.L., H.W.T.], Department of Anesthesiology and Surgery [J.F.P.], \\ San Francisco General Hospital/University of California-San Francisco, San Francisco, California \\ 94110; Department of Physiology [J.G.], Department of Pediatrics and Cardiovascular Research Institute \\ [J.C., L.A.], University of California-San Francisco, San Francisco, California, 94143
}

\begin{abstract}
Addition of ionic and nonionic water-soluble polymers to pulmonary surfactants in the presence of inactivating substances prevents surfactant inactivation in vitro and improves lung function in several models of lung injury. However, a recent report found opposite effects when surfactant plus polyethylene glycol (PEG) was used to treat lung injury caused by saline lung lavage. Therefore, we examined the reasons why the polymer effect is less evident in the saline lung lavage lung injury model. We treated rats with lavage lung injury with a commercial lung surfactant extract derived from bovine lung (Survanta) with or without addition of PEG. Groups treated with Survanta + PEG had significantly higher static post mortem lung volumes than groups treated with Survanta. However, groups treated with Survanta + PEG had more tracheal fluid and no significant
\end{abstract}

benefit in arterial oxygenation compared with the group treated with Survanta, despite our use of measures to reduce pulmonary edema. Measurements after intravascular injections of ${ }^{125} \mathrm{I}$-labeled albumin confirmed that addition of PEG increased extravascular lung water and that this effect is mitigated by furosemide. We conclude that surfactant + PEG mixtures are less effective in lavage injury than in other forms of lung injury because of increased extravascular lung water. (Pediatr Res 58: 913-918, 2005)
ALI, acute lung injury
Abbreviations
ARDS, acute respiratory distress syndrome
PEEP, positive end-expiratory pressure
PEG, polyethylene glycol

ALI results from a variety of insults as diverse as meconium aspiration in newborns, hydrochloric acid reflux, sepsis, and ventilator trauma. In turn, injury predisposes the patient to acute (or adult) respiratory distress syndrome (ARDS) (1-4). Pulmonary surfactant replacement, now a mainstay in the treatment of respiratory distress syndrome in premature infants, has not enjoyed comparable success in treating ARDS (5-7). Inadequate dosage or distribution, and inactivation of surfactant have been postulated for its poor performance in treating these injuries $(8-11)$.

Multiple reports indicate improved surfactant function when polymers such as dextrans, PEG, and hyaluronan are added to surfactant preparations in vitro (12-15). Animals with ALI have improved lung function when treated with surfactant polymer mixtures versus surfactant alone. Lu et al. (16-18)

Received January 4, 2005; accepted April 11, 2005.

Correspondence: H. William Taeusch, M.D., San Francisco General Hospital, Department of Pediatrics, MS 6E, 1001 Potrero Ave., San Francisco, CA 94110; e-mail: btaeusch@sfghpeds.ucsf.edu

Supported in part by grants from Ross Labs and the University of California-San Francisco Committee on Research, and National Institutes of Health grants HL 66410 and HL 24075.

DOI: 10.1203/01.PDR.0000182581.39561.01 found that adult rats receiving surfactant + PEG, dextran, or hyaluronan mixtures have better gas exchange, pulmonary mechanics, and histologic appearance of the lungs when compared with rats treated with Survanta (beractant) alone after $\mathrm{HCl}$, meconium-, and endotoxin-induced lung injuries. Kobayashi et al. $(19,20)$ have shown that addition of dextran to surfactant improves responses in two additional lung injury models (albumin inhibition in immature rabbits and acid milk aspiration in rats).

The specific model used to induce ALI, however, may affect treatment responses to surfactant and surfactant + PEG, as different models of lung injury produce different alveolar environments. A lavage model of lung injury, for example, removes variable amounts of alveolar surfactant (21), whereas a meconium model of lung injury inactivates but does not remove surfactant. Puligandla et al. (22) have demonstrated the varied effects of different lung injury models on the properties of exogenous surfactants, noting differences in large aggregate pool sizes, surface activity, and alterations in phospholipid and protein content in recovered exogenous surfactant.

Providing an illustration of this point, a recent study by Campbell et al. (23) of lavage-injured adult rabbits has produced results inconsistent with the positive results seen with 
PEG in a different lung injury model. Animals treated with surfactant + PEG in their study exhibited more hypoxemia, lower lung compliance, and hypercapnia when compared with animals receiving only surfactant. Why addition of polymers to surfactants improved responses after meconium, endotoxin, $\mathrm{HCl}$, and albumin-immaturity injuries but worsened responses in lavage injury is not clear. Our initial hypothesis, like that of Campbell et al., was that PEG surfactant mixtures would improve lung mechanics and gas exchange in a lavage model of lung injury. When we found results that were less dramatic than we had found using this treatment in other lung injuries, we tested whether the suboptimal effects were associated with increased lung water that could be attributable to the osmolarity of the added PEG.

\section{METHODS}

The animal protocol used was approved by the committee on animal research at the University of California-San Francisco. The general design of these experiments was to anesthetize and paralyze adult rats, create lung injury by saline lung lavage until target $\mathrm{PO}_{2}$ values were achieved, administer furosemide, then treat the rats with different doses of Survanta or Survanta + PEG. The seven experimental groups consisted of no treatment $(n=3)$, Survanta $20 \mathrm{mg} / \mathrm{kg} \pm$ PEG (10 kD, 5\% wt/vol), Survanta $25 \mathrm{mg} / \mathrm{kg} \pm \mathrm{PEG}$, and Survanta $50 \mathrm{mg} / \mathrm{kg} \pm$ PEG (treatment groups: $n=6-7$ ). With results of these experiments in hand, using a slightly modified protocol, we studied the specific effects of PEG and furosemide on extravascular lung water and capillary leak using ${ }^{125}$ I-labeled albumin as a marker.

Lavage procedure. We chose to use rats for these experiments based on our extensive experience with lung injuries in this species $(16,18)$. After randomization, white adult male Sprague-Dawley rats weighing 267-411 g were anesthetized by intraperitoneal injection of $100 \mathrm{mg} / \mathrm{kg}$ pentobarbital at 50 $\mathrm{mg} / \mathrm{mL}$. After tracheostomy, the rats were supported on a Harvard volumecontrolled ventilator (Harvard small rodent ventilator, model 683; Harvard Apparatus, South Natick, MA) with initial settings of frequency $=40$ breaths/ min, tidal volume $=9 \mathrm{~mL} / \mathrm{kg}$ body weight, $\mathrm{PEEP}=4 \mathrm{~cm}$ water, $\mathrm{FiO}_{2}=1.0$, and flow rate $=0.5 \mathrm{~L} / \mathrm{min}$. The right carotid artery was catheterized for monitoring of systemic arterial blood pressure, collection of blood gas samples, and drug and fluid administration. Systemic arterial blood pressure and tracheal pressure measurements were recorded every $30 \mathrm{~min}$ throughout the experiment. Rats with a systemic blood pressure $<100 \mathrm{~mm} \mathrm{Hg}$ after $30 \mathrm{~min}$ on the ventilator were observed for an additional $45 \mathrm{~min}$ and removed from the study if the blood pressure remained $<100 \mathrm{~mm} \mathrm{Hg}$. The carotid catheter was flushed with a 10 units heparin $/ \mathrm{mL}$ normal saline solution after arterial blood gas collection and drug administration. Blood pressure and tracheal pressures were measured using Viggo-Spectromed transducers (Gould model P23XL) attached to a recorder (Gould Windowgraf, Gould, Valley View, OH).

Intra-arterial pancuronium $(1 \mathrm{mg} / \mathrm{kg})$ was administered at the start of the experiment (18), and $0.5 \mathrm{mg} / \mathrm{kg}$ was given every hour. Intra-arterial pentobarbital $(7 \mathrm{mg} / \mathrm{mL})$ was given in $0.1 \mathrm{~mL}$ increments throughout the experiment to maintain systolic blood pressure $<125 \mathrm{~mm} \mathrm{Hg}$ and for response to skin pinch. The rats were maintained under an overhead heat lamp $(50 \mathrm{~W})$ with measurements of rectal temperature (Digi-Sense, Cole-Parmer, Vernon Hills, IL). A baseline arterial blood gas was recorded $15 \mathrm{~min}$ after placement on the ventilator and every $10-15$ min thereafter until stable values were obtained (target $\mathrm{PCO}_{2}=35-50 \mathrm{~mm} \mathrm{Hg}$ ). The respiratory frequency was adjusted by five breaths per minute every 15 min to maintain $\mathrm{PCO}_{2}$ within the desired limits. Rats for which we could not achieve stable $\mathrm{PCO}_{2}, \mathrm{~S}$ after three respiratory rate changes were excluded from the study.

Thirty minutes after placement on the ventilator, tracheal lavage with $0.9 \%$ $\mathrm{NaCl}$ at $37^{\circ} \mathrm{C}$ was carried out by disconnecting the animals from the ventilator and carrying out the lavage procedure. Rats were lavaged three times with 10 $\mathrm{mL} / \mathrm{kg}$ per lavage. The chest was compressed twice and the rats were reconnected to the ventilator for 5-10 s and aspirated lavage fluid volume was recorded. This procedure was carried out an additional five times. PEEP was increased to $8 \mathrm{~cm} \mathrm{H}_{2} \mathrm{O}$ and maintained at that level for the duration of the experiment. The rats were then placed back on the ventilator for 5 min and placed on their sides if hypotension occurred (blood pressure $<75 \mathrm{~mm} \mathrm{Hg}$ ) to decompress the great vessels. Blood and tracheal pressures were recorded immediately before and after each lavage series. Five minutes after the sixth lavage procedure, an arterial blood gas was obtained. If the blood gas revealed a $\mathrm{Po}_{2}>100 \mathrm{~mm} \mathrm{Hg}$ (which was rare), the rats were subjected to additional lavage procedures until a $\mathrm{PO}_{2}<100 \mathrm{~mm} \mathrm{Hg}$ was obtained (24).
Thirty minutes after the last lavage, an arterial blood gas was recorded and $10 \mathrm{mg} / \mathrm{kg}$ of intra-arterial furosemide $(10 \mathrm{mg} / \mathrm{mL})$ was administered. We use diuretic for several reasons: we used it in our meconium lung injury model adapted from the work of Sun et al. (25), and we thought it especially relevant to include with the wet lung injury produced by lavage. If the osmotic effects of PEG are important in vivo, then inclusion of diuretic could be relevant to eventual clinical use. Thirty minutes later, another arterial blood gas was recorded and treatment was given. Treatment consisted of Survanta at 20, 25, or $50 \mathrm{mg} / \mathrm{kg}$. The stock $25 \mathrm{mg} / \mathrm{mL}$ Survanta solution was diluted to a treatment volume of $4 \mathrm{~mL} / \mathrm{kg}$ with $0.45 \% \mathrm{NaCl}$ and mixed by Vortex for $30 \mathrm{~s}$ (Fisher Vortex, model G-560; Fisher Scientific, Pittsburgh, PA). Survanta was supplied by Ross Laboratories (Columbus, $\mathrm{OH}$ ). Surface tension of the Survanta was tested in a modified pulsating bubble surfactometer (Electronetics, Buffalo, NY) at a concentration of $1.25 \mathrm{mg} / \mathrm{mL}$. Minimal surface tension in the pulsating bubble surfactometer was assessed at $37^{\circ} \mathrm{C}$ on the 10th cycle and in all cases was $<10 \mathrm{mN} / \mathrm{m}$. PEG (molecular weight, $10 \mathrm{kD}$; Lot $115 \mathrm{H} 26011$ ) was obtained from Sigma Chemical Co. (St. Louis, MO) as dry crystalline flakes. Dry PEG (5\% wt/vol) was added to the diluted treatment mixtures and mixed by Vortex. The treatment mixture was instilled into the trachea, with half the dose given while the rats were on each side. Control rats received no treatment. Arterial blood gases were recorded 30 and $60 \mathrm{~min}$ after treatment, then hourly until the end of the experiment. Tracheal fluid was aspirated with a 3-mL syringe attached to a PE 50 catheter introduced into the tracheal tube to the level of the carina (16) $1 \mathrm{~h}$ after treatment and hourly thereafter.

Volume of tracheal fluid was measured and the fluid assayed for total protein using the Bradford protein assay (26). Survanta + PEG samples were compared with a standard curve constructed with 5\% PEG and bovine albumin (lyophilized BSA, \#68530A; Bio-Rad, Hercules, CA). Control and Survanta samples were compared with standard curves constructed with bovine albumin alone.

Three hours after treatment, intra-arterial pentobarbital $(33 \mathrm{mg} / \mathrm{kg}$ ) was administered and the trachea was clamped. Twenty minutes after pentobarbital administration, the abdomen and diaphragm were opened widely. Adequate degassing of the lungs was confirmed by the appearance of maroon-colored (airless) lungs. Lungs from rats who died before the end of the experiment or whose lungs did not appear airless were degassed in a bell jar connected to a vacuum pump (Maxima Vacuum, Model D8A, Fisher Scientific).

Deflation pressure-volume measurements. Postmortem quasi-static deflation pressure-volume measurements on open-chested animals were performed by inflating the lungs to a pressure of $35 \mathrm{~cm} \mathrm{H}_{2} \mathrm{O}$ using a 20-mL syringe. After a 30 -s period of stabilization, volume was measured to define total lung capacity. Pressure was reduced in steps of $5 \mathrm{~cm} \mathrm{H}_{2} \mathrm{O}$ with at least a 10-s stabilization period at each step, and the corresponding volumes were measured. Volume was corrected for compression in the dead space of the apparatus and expressed as milliliters per kilogram of body weight (16).

Histology. After the standardized lung inflation for pressure-volume measurements, lungs were removed and weighed, and a mid-sagittal slice of the left lung was fixed in $4 \%$ formaldehyde, embedded in paraffin, and stained with hematoxylin and eosin. The sections were coded so that the specimens were graded by two investigators without knowledge of the experimental groupings. The sections were examined by light microscopy and assessed for the presence of hemorrhage, atelectasis, and leukocytes. Each characteristic was scored 0 to 3 ( 0 = absent; $1=$ mild; $2=$ moderate; $3=$ prominent $)$. Scores by the two observers did not differ by more than $15 \%$.

Electron microscopy. Transmission electron microscopy was performed on Survanta with or without 5\% PEG. Pellets $(10,000 \mathrm{rpm}, 1 \mathrm{~h})$ of Survanta or Survanta + PEG were fixed in $2 \%$ glutaraldehyde, $1 \% \mathrm{OsO}_{4}$ in $0.1 \mathrm{M}$ cacodylate buffer ( $\mathrm{pH} 7.4$ ) for $24 \mathrm{~h}$ at $4 \mathrm{C}$. The samples were further stabilized and stained en bloc in $2 \%$ aqueous uranyl acetate for $48 \mathrm{~h}$. The pellets were dehydrated quickly in cold acetone, brought to room temperature in $100 \%$ acetone, then slowly infiltrated with increasing concentrations of LX 112 (Ladd Research Industries, Burlington, VT), left overnight in 100\% LX 112, and finally embedded. Thin sections were cut and stained with 5\% uranyl acetate and $0.8 \%$ lead citrate, then examined in a Zeiss 10 transmission electron microscope (Carl Zeiss, Thornwood, NY).

Lung water experiments. An additional series of animals were studied to assess the effects of PEG added to surfactant and/or furosemide on pulmonary edema (excess extravascular lung water in milliliters) measured by the gravimetric method, and endothelial permeability to albumin measured by extravasation of vascular ${ }^{125}$ I-labeled albumin (27). Rats were prepared and given lung injury as described above, but the lavage was standardized to give five lavages of $30 \mathrm{~mL} / \mathrm{kg}$ body weight. Six experimental groups $(n=3)$ were studied consisting of 1) uninjured and untreated (U, U);2) uninjured and PEG $(\mathrm{U}, \mathrm{P}) ; 3$. Survanta $25 \mathrm{mg} / \mathrm{kg}$ and furosemide after injury (I, S, F); 4) Survanta $25 \mathrm{mg} / \mathrm{kg}$ with PEG and furosemide after injury (I, S, P, F,); 5) Survanta 25 $\mathrm{mg} / \mathrm{kg}$ with PEG after injury (I, S, P); and 6) injury and PEG (I, P). In these experiments, Survanta was diluted to the appropriate concentration with $0.9 \%$ $\mathrm{NaCl}$ (not $0.45 \% \mathrm{NaCl}$ as used in the initial experiments). At the time of 
treatment, $1 \mu \mathrm{c}$ of ${ }^{125}$ I-labeled albumin in $1 \mathrm{~mL}$ saline was injected into the artery, with blood samples taken at $5 \mathrm{~min}, 1 \mathrm{~h}$, and $2 \mathrm{~h}$ thereafter. At the end of the experiment, the lungs were removed and weighed. ${ }^{125} \mathrm{I}$ counts per minute, $\mathrm{Hb}$, and wet/dry weights were obtained on lung homogenates, and excess lung water was calculated by the gravimetric method. No aspiration of tracheal fluid was done in these experiments.

Extravascular plasma equivalents (EVPE) were measured by the following formula:

$$
\mathrm{EVPE}=\left[\mathrm{C}_{\mathrm{H}}-\left(\mathrm{C}_{\text {pend }} \times \mathrm{Q}_{\mathrm{B}}\right)\right] / \mathrm{C}_{\text {Pave }}
$$

where, $\mathrm{EVPE}=\mu \mathrm{l} / \mathrm{g}$ dry lung weight; $\mathrm{C}_{\mathrm{H}}=$ counts per $\mathrm{min} / \mathrm{g}$ in the homogenized lung; $\mathrm{C}_{\text {pend }}=$ the count per $\mathrm{min} / \mathrm{g}$ in plasma samples at the end of the experiment; $Q_{B}=$ the blood volume in the lungs determined by the gravimetric method; and $\mathrm{C}_{\mathrm{Pave}}=$ the average counts per $\mathrm{min} / \mathrm{g}$ in the plasma samples collected at $5 \mathrm{~min}, 1 \mathrm{~h}$, and $2 \mathrm{~h}$.

Analyses. Data are expressed as mean \pm SEM. Serial measurements were analyzed by two-way ANOVA modified for repeated measures using SigmaStat software (SPSS Science, Chicago, IL). Univariate analyses were done for nonserial data and differences were compared using the $t$ test, with $p<0.05$ considered statistically significant.

\section{RESULTS}

General findings. Four of the 40 rats randomized in the initial study died during the experiment ( 1 from the Survanta $25 \mathrm{mg} / \mathrm{kg}$ group, 1 from the Survanta $25 \mathrm{mg} / \mathrm{kg}+$ PEG group, and 2 from the Survanta $50 \mathrm{mg} / \mathrm{kg}+$ PEG group). The number of lavages ranged between seven and nine per rat, with 88 $91 \%$ of the lavage fluid recovered (no statistically significant differences among groups). There were no significant differences between groups treated with Survanta or Survanta + PEG with regard to blood pressure, peak inspiratory pressures, body weight, fluid administration, rectal temperature, or urinary output. No significant differences existed between Survanta and Survanta + PEG for pretreatment $\mathrm{pH}, \mathrm{PCO}_{2}, \mathrm{Po}_{2}$, or base deficit.

Oxygenation. Average values for arterial oxygenation for the various groups are shown in Figure 1. A significant dose response was noted only when the 25 and $50 \mathrm{mg} / \mathrm{kg}$ groups were compared with the $20 \mathrm{mg} / \mathrm{kg}$ group. There were no significant differences between Survanta and Survanta + PEG group at any dose. Average oxygenation for groups treated with Survanta or Survanta + PEG was significantly better than oxygenation for the control (untreated) group.

Pressure-volume relationships. In general, pressure-volume measurements indicated that lung volumes were higher in the groups treated with Survanta + PEG. Pressure-volume curves were significantly improved for Survanta + PEG groups (50 and $25 \mathrm{mg} / \mathrm{kg}$ ) but not for $20 \mathrm{mg} / \mathrm{kg}$ when compared with
Survanta alone (ANOVA for repeated measures) (Fig. 2). Pressure-volume curves were significantly left-shifted for the Survanta $50 \mathrm{mg} / \mathrm{kg}+$ PEG group when compared with the Survanta $25 \mathrm{mg} / \mathrm{kg}+$ PEG group $(p=0.025)$ and the 20 $\mathrm{mg} / \mathrm{kg}+$ PEG group $(p<0.001)$.

Histology. In control animals, lavage injury was similar to that reported by Berggren et al. (28), with atelectasis and an influx of white and red cells. Significantly reduced scores $(p<$ 0.05 ) for atelectasis and presence of white and red blood cells were found as the dose of Survanta was increased from 20 or $25 \mathrm{mg} / \mathrm{kg}$ to $50 \mathrm{mg} / \mathrm{kg}$. There was no difference for any histologic variable between Survanta and Survanta + PEG groups at corresponding doses.

Lung water and capillary leak. The Survanta + PEG groups had greater volumes of tracheal fluid recovered in the $3 \mathrm{~h}$ after treatment at each dose when compared with Survanta groups ( $p$ $<0.01$ for all three groups) (Fig. 3). Less tracheal fluid was obtained from animals treated with 50 and $25 \mathrm{mg} / \mathrm{kg}$ Survanta + PEG than from those treated with $20 \mathrm{mg} / \mathrm{kg}$ Survanta + PEG $(p<0.05)$.

Protein concentrations of the tracheal fluids were significantly higher in the Survanta $20 \mathrm{mg} / \mathrm{kg}$ group than the Survanta 20,25 , and $50 \mathrm{mg} / \mathrm{kg}+$ PEG groups $(p<0.01)$ (Fig. 4). There was no difference in protein concentration among the three Survanta + PEG groups. Since no tracheal fluid was recovered from Survanta $25 \mathrm{mg} / \mathrm{kg}$ or Survanta $50 \mathrm{mg} / \mathrm{kg}$ animals, protein measurements were not possible for these groups.

Wet lung weights (expressed as a percentage of body weight) appeared higher in all Survanta + PEG groups when compared with the corresponding Survanta groups, but differences were not significant. When the volume of tracheal aspirate recovered from each rat was added to the wet lung weight (and expressed as a percentage of body weight), all Survanta + PEG groups had significantly higher lung weight/body weight ratios than the corresponding Survanta groups ( $p<0.01$ for all groups).

Results from experiments designed specifically to study capillary leak are shown in Figure 5. Excess extravascular lung water (EELW) was significantly increased when injured animals receiving furosemide were treated with Survanta + PEG or PEG and were compared with Survanta (Fig. 5A). Furosemide significantly diminished the amount of lung water in the Survanta + PEG group (Fig. 5A). Wet/dry ratios are
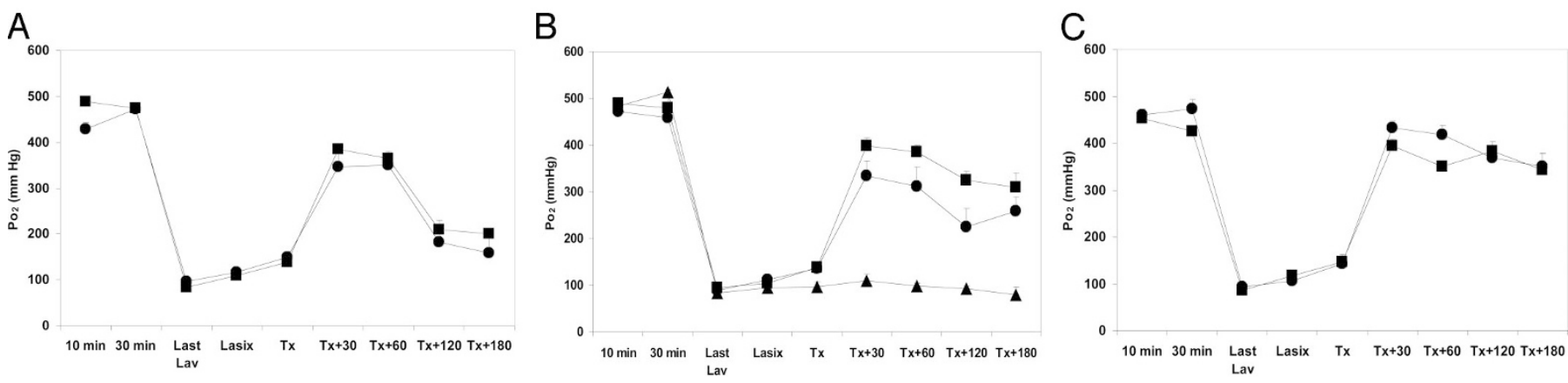

Figure 1. Comparisons of mean $\mathrm{Po}_{2}$ values between Survanta (circles) and Survanta + PEG (squares) at $(A) 20$, (B) 25 , and $(C) 50 \mathrm{mg} / \mathrm{kg}(n=6-7 / \mathrm{treatment}$ group). No significant differences between Survanta and Survanta + PEG at any dose are found (Lasix $=$ furosemide). Triangles in $B$ represent the means for the control (untreated) group $(n=3)$. 

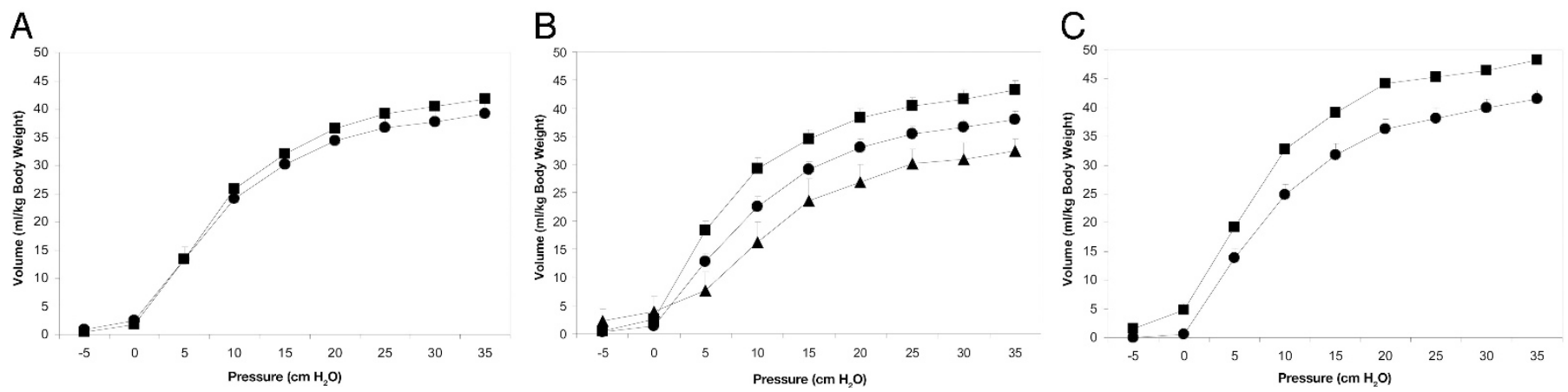

Figure 2. Deflation pressure/volume curves comparing Survanta (circles) and Survanta + PEG (squares) at doses of $(A) 20 \mathrm{mg} / \mathrm{kg}$, (B) $25 \mathrm{mg} / \mathrm{kg}$ ), and (C) $50 \mathrm{mg} / \mathrm{kg}(n=6-7 /$ treatment group). Triangles in $B$ represent the means for the control (untreated) group $(n=3)$. Lung volumes are significantly improved with Survanta + PEG at $25(p=0.03)$ and $50 \mathrm{mg} / \mathrm{kg}(p=0.001)$ compared with those treated with Survanta alone.

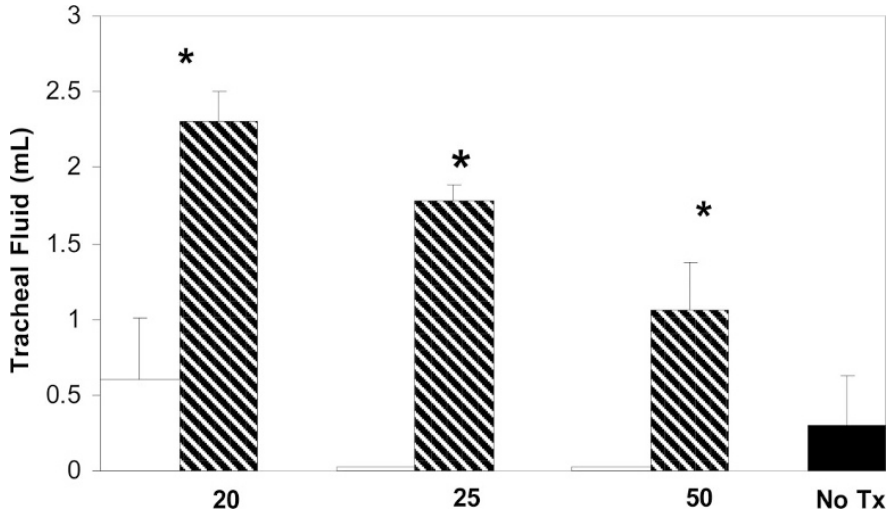

Figure 3. Aspirated tracheal fluid volumes are shown. Statistical significance $(p<0.01)$ denoted with an asterisk. Those treated with Survanta + PEG had an increased amount of tracheal fluid at all three surfactant dosages compared with Survanta alone. Open bars, Survanta; hatched bars, Survanta + PEG; solid bar, control (untreated) group.

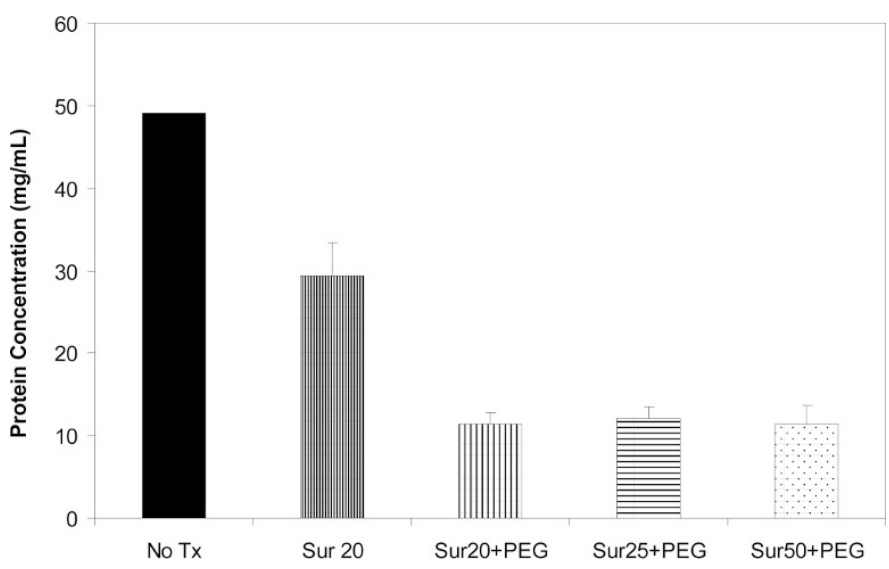

Figure 4. Protein concentrations of tracheal fluid are shown. Animals treated with Survanta $20 \mathrm{mg} / \mathrm{kg}$ had higher protein concentrations than any PEGtreated group $(p<0.01)$. No difference was found among the Survanta + PEG-treated groups. Animals in the Survanta 25 and $50 \mathrm{mg} / \mathrm{kg}$ groups produced no tracheal fluid.

significantly greater in the injured Survanta + PEG groups with or without furosemide when compared with the uninjured and untreated. The comparison between the injured group versus the noninjured group, both treated with PEG, was also significantly different (Fig. 5B). Average EVPE were not significantly different among the six groups.
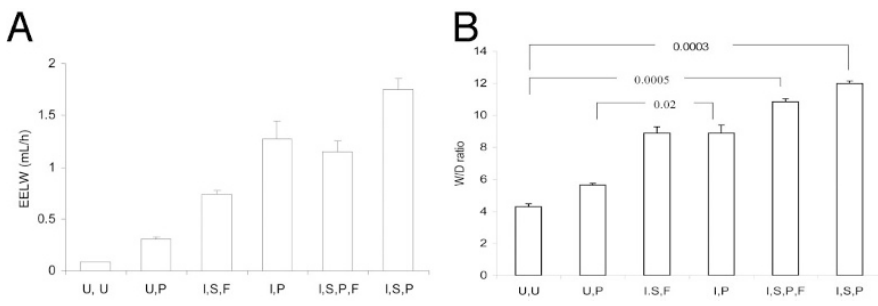

Figure 5. Data are from experiments specifically designed to study lung water $(n=3)$. (A) Excess extravascular lung water (EELW, $\mathrm{mL} / \mathrm{h})$ is significantly greater in the injured group treated with Survanta + PEG and furosemide (I, $\mathrm{S}, \mathrm{P}, \mathrm{F}) v s$ the group treated with Survanta and furosemide (I, S, F) $(p=0.04)$ or when the Survanta + PEG group (I, S, P) is compared with Survanta + PEG with furosemide $(\mathrm{I}, \mathrm{S}, \mathrm{P}, \mathrm{F})(p=0.01)$. When comparing uninjured and untreated $(\mathrm{U}, \mathrm{U})$ animals with those that were uninjured and treated with PEG $(\mathrm{U}, \mathrm{P}), p=0.005$. $(B)$ Lung wet and dry weight ratios are shown. Wet/dry ratios are significantly greater in the injured Survanta + PEG groups with or without furosemide (I, S, P, F or I, S, P) when compared with the uninjured and untreated $(\mathrm{U}, \mathrm{U})$. The comparison between the injured group $v s$ the noninjured group, both treated with PEG (I, P vs U, P), was also significantly different.

Electron microscopy. Comparison of electron photomicrographs of Survanta and Survanta + PEG indicated more multilamellar structures were seen in the Survanta/PEG mixtures. (Fig. 6). These changes imply that the vesicles coalesce into membranous structures in the presence of PEG.

\section{DISCUSSION}

The addition of PEG to Survanta in this study improved quasistatic mechanical properties but not serial measures of gas exchange. Significant increases of lung volumes during performance of deflation pressure-volume curves were found with Survanta + PEG groups at doses of 25 and $50 \mathrm{mg} / \mathrm{kg}$. Several lines of evidence suggest increased alveolar fluid volume occurs when PEG is added to surfactant. Aspirated tracheal fluid volume increased with lower dosage of surfactant in the presence of PEG. In addition, extravascular lung water but not alveolar protein was increased in animals receiving Survanta + PEG or PEG alone. In contrast to the results of Campbell et al. (23), we found no worsening of gas exchange in Survanta + PEG-treated animals compared with animals treated with Survanta.

Increased pulmonary fluid may be secondary to an osmotic effect of PEG reducing clearance of pulmonary edema. Also, epithelial injury in the face of continued accumulation of alveolar fluid may overwhelm the ability of the epithelium to 


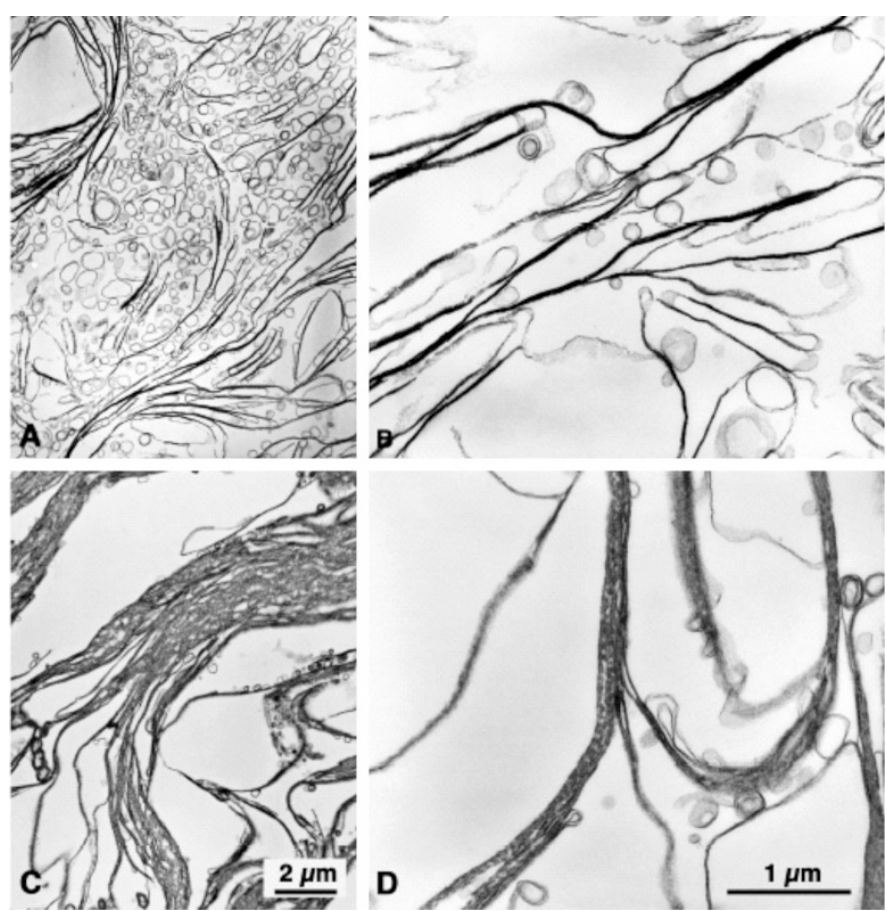

Figure 6. Transmission electron micrographs of Survanta are shown. ( $A$ and $B$ ) Survanta; $(C$ and $D)$ Survanta + PEG. $A$ and $C$ are low magnification and $B$ and $D$ are high magnification. More membranous structures are seen after adding PEG to Survanta.

transport fluid out of the alveoli $(29,30)$. Interpolating from measurements reported by MacDonald (31), we estimate osmolarity of 5\% PEG to be two to three times that of plasma colloid osmotic pressure. Therefore, depending on a variety of factors (PEEP, plasma oncotic and hydrostatic pressures, alveolar surface tension, degree of epithelial and endothelial damage, effectiveness of cellular clearance mechanisms for alveolar water, and amount of water bound to PEG), alveolar water could be increased by the presence of an osmotically active agent like PEG. All groups in this study had estimates of lung fluid at the end of the experiment in the range of $14-40 \%$ of total lung volumes (at pressures of $35 \mathrm{~cm} \mathrm{H}_{2} \mathrm{O}$ ). This excess fluid burden, in an animal expected to develop additional alveolar fluid from this kind of lung injury itself, may prove too much for the animal to clear in the presence of PEG.

Our results differ to some degree from those of Campbell et al. (23). They found diminished serial measures of $\mathrm{Po}_{2}$ in rabbits treated with either 100 or $25 \mathrm{mg} / \mathrm{kg}$ Survanta with PEG compared with Survanta alone. Differences may be explained by use of different species, the degree of injury, and alterations in ventilator use. Our use in the initial studies of a hypoosmotic vehicle for diluting surfactant, a diuretic, relatively high PEEP, and regular tracheal suctioning may also have mitigated the buildup of pulmonary fluid with PEG, and hence explain the discrepancies in gas exchange seen between our study and that of Campbell et al. (23).

The rationale for adding PEG (or dextran) to surfactants is that PEG reduces inactivation of surfactant and enhances rates of surfactant transfer from bulk lipid to air liquid surfaces $(15,32)$. Treatment of ALI with inactivation-resistant surfactants may im- prove responses to therapy. However, if addition of PEG increases alveolar water, then positive effects may be attenuated. Good evidence indicates that alveolar fluid is increased in some patients with ARDS and that mechanisms for clearance of alveolar water are impaired, especially in those patients with poor outcomes (33). However, in prior work, we and others have found that addition of polymers to surfactant improves responses in different animal models of ALI, suggesting that they have positive, not detrimental, effects in these forms of ALI although detailed measurements of lung water were not carried out (16,18-20).

The osmotic effects of PEG and dextran may be, in part, responsible for their effects on surfactant function. Polymers cause dehydration of spaces between lipid vesicles setting up depletion forces that cause lipid aggregation as well as improved function of surfactants in vitro $(15,31,32,34)$. Electron micrographs indicate that PEG is associated with a change in form of Survanta, from vesicles to thickened membranous structures.

For surfactants improved by addition of PEG or other polymers $(12,17,19,35)$ to be clinically useful, our data, coupled with the observations of Campbell et al. (23), indicate that careful matching of surfactant quality with the specific intraalveolar pathology may be necessary as implied by the work of Puligandla et al. (22). This approach may in time significantly improve surfactant therapy for ALI/ARDS. In summary, after measures were taken to reduce lung water, we find no evidence that PEG-Survanta mixtures worsen pulmonary function after lavage-high tidal volume injury. In two of the three treatment groups, addition of PEG to Survanta improved pressurevolume relationships. Nonetheless, lung lavage produces a form of ALI in which responses to surfactant plus polymer mixtures are less than with other experimental models of ALI, probably due to increases in lung water. Although evidence remains strong that addition of nonionic and ionic polymers can reduce inactivation of surfactant and improve lung function after some types of ALI, osmotic effects may constitute a risk with these additives. More study is needed to understand how polymers affect function of pulmonary surfactants in vitro and in vivo, and to identify polymer-surfactant mixtures that have positive, or, at least, negligible, effects on fluid balance in the lungs of animals with acute lung injury.

\section{REFERENCES}

1. Fulkerson WJ, MacIntyre N, Stamler J, Crapo JD 1996 Pathogenesis and treatment of the adult respiratory distress syndrome. Arch Intern Med 156:29-38

2. Hudson LD, Steinberg KP 1999 Epidemiology of acute lung injury and ARDS. Chest 116:74S-82S

3. Matthay MA 1999 Conference summary: acute lung injury. Chest $116: 119 \mathrm{~S}-126 \mathrm{~S}$

4. Lewis JF, Brackenbury A 2003 Role of exogenous surfactant in acute lung injury. Crit Care Med 31:S324-S328

5. Gregory TJ, Steinberg KP, Spragg R, Gadek JE, Hyers TM, Longmore WJ, Moxley MA, Cai GZ, Hite RD, Smith RM, Hudson LD, Crim C, Newton P, Mitchell BR, Gold AJ 1997 Bovine surfactant therapy for patients with acute respiratory distress syndrome. Am J Respir Crit Care Med 155:1309-1315

6. Anzueto A, Baughman R, Guntupalli KK, Weg JG, Wiedemann HP, Raventós AA, Lemaire F, Long W, Zaccardelli DS, Pattishall EN 1996 Aerosolized surfactant in adults with sepsis-induced acute respiratory distress syndrome. Exosurf Acute Respiratory Distress Syndrome Sepsis Study Group. N Engl J Med 334:1417-1421

7. Spragg RG, Lewis JF, Walmrath HD, Johannigman J, Bellingan G, Laterre PF, Witte MC, Richards GA, Rippin G, Rathgeb F, Hafner D, Taut FJ, Seeger W 2004 Effect of recombinant surfactant protein C-based surfactant on the acute respiratory distress syndrome. N Engl J Med 351:884-892

8. Seeger W, Gunther A, Walmrath HD, Gimminger F, Lasch HG 1993 Alveolar surfactant and adult respiratory distress syndrome. Pathogenetic role and therapeutic prospects. Clin Investig 71:177-190 
9. Jobe AH, Ikegami M 1997 Surfactant for acute respiratory distress syndrome. Adv Intern Med 42:203-230

10. Taeusch HW 2000 Treatment of acute (adult) respiratory distress syndrome. The holy grail of surfactant therapy. Biol Neonate 77(Suppl 1):2-8

11. Baudouin S 2004 Exogenous surfactant replacement in ARDS-one day, someday, or never? N Engl J Med 351:853-855

12. Tashiro K, Kobayashi T, Robertson B 2000 Dextran reduces surfactant inhibition by meconium. Acta Paediatr 89:1439-1445

13. William Taeusch H, Lu KW, Goerke JA, Clements J 1999 Nonionic polymers reverse inactivation of surfactant by meconium and other substances. Am J Respir Crit Care Med 159:1391-1395

14. Lu KW, Goerke J, Clements JA, Taeusch HW 2005 Hyaluronan decreases surfactant inactivation in vitro. Pediatr Res 57:237-241

15. Yu LM, Lu JJ, Chiu IW, Leung KS, Chan YW, Zhang L, Policova Z, Hair ML, Neumann AW 2004 Poly (ethylene glycol) enhances the surface activity of a pulmonary surfactant. Colloids Surf B Biointerfaces 36:167-176

16. Lu KW, Taeusch HW, Robertson B, Goerke J, Clements JA 2001 Polyethylene glycol/surfactant mixtures improve lung function after $\mathrm{HCl}$ and endotoxin lung injuries. Am J Respir Crit Care Med 164:1531-1536

17. Lu K, Goerke J, Clements J, Taeusch HW 2005 Hyaluronan reduces surfactant inhibition and improves rat lung function after meconium injury. Pediatr Res 58:206-210

18. Lu KW, William Taeusch H, Robertson B, Goerke J, Clements JA 2000 Polymersurfactant treatment of meconium-induced acute lung injury. Am J Respir Crit Care Med 162:623-628

19. Kobayashi T, Ohta K, Tashiro K, Nishizuka K, Chen WM, Ohmura S, Yamamoto K 1999 Dextran restores albumin-inhibited surface activity of pulmonary surfactant extract. J Appl Physiol 86:1778-1784

20. Cui XG, Tashiro K, Matsumoto H, Tsubokawa Y, Kobayashi T 2003 Aerosolized surfactant and dextran for experimental acute respiratory distress syndrome caused by acidified milk in rats. Acta Anaesthesiol Scand 47:853-860

21. Notter RH 2000 Lung Surfactants: Basic Science and Clinical Applications. Marcel Dekker Inc., New York, pp 268

22. Puligandla PS, Gill T, McCaig LA, Yao LJ, Veldhuizen RA, Possmayer F, Lewis JF 2000 Alveolar environment influences the metabolic and biophysical properties of exogenous surfactants. J Appl Physiol 88:1061-1071
23. Campbell H, Bosma K, Brackenbury A, McCaig L, Yao LJ, Veldhuizen R, Lewis J 2001 Polyethylene glycol (PEG) attenuates exogenous surfactant in lung-injured adult rabbits. Am J Respir Crit Care Med 165:475-480

24. Lachmann B, Robertson B, Vogel J 1980 In vivo lung lavage as an experimental model of the respiratory distress syndrome. Acta Anaesthesiol Scand 24:231-236

25. Sun B, Curstedt T, Robertson B 1996 Exogenous surfactant improves ventilation efficiency and alveolar expansion in rats with meconium aspiration. Am J Respir Crit Care Med 154:764-770

26. Bradford MM 1976 A rapid and sensitive method for the quantitation of microgram quantities of protein utilizing the principle of protein-dye binding. Anal Biochem $72: 248-254$

27. Frank JA, Gutierrez JA, Jones KD, Allen L, Dobbs L, Matthay MA 2002 Low tidal volume reduces epithelial and endothelial injury in acid-injured rat lungs. Am J Respi Crit Care Med 165:242-249

28. Berggren P, Lachmann B, Curstedt T, Grossman G, Robertson B 1986 Gas exchange and lung morphology after surfactant replacement in experimental adult respiratory distress syndrome induced by repeated lung lavage. Acta Anaesthesiol Scand 30:321-328

29. Crandall EE, Matthay MA 2001 Alveolar epithelial transport. Basic science to clinical medicine. Am J Respir Crit Care Med 162:1021-1029

30. Modelska K, Pittet JF, Folkesson HG, Courtney Broaddus V, Matthay MA 1999 Acid-induced lung injury. Protective effect of anti-interleukin- 8 pretreatment on alveolar epithelial barrier function in rabbits. Am J Respir Crit Care Med 160:1450-1456

31. MacDonald RI 1985 Membrane fusion due to dehydration by polyethylene glycol, dextran, or sucrose. Biochemistry 24:4058-4066

32. Kuhl T, Guo Y, Aldefer JL, Berman AD, Leckband D, Israelachvili J, Hui SW 1996 Direct measurement of polyethylene glycol induced depletion attraction between lipid bilayers. Langmuir 12:3003-3014

33. Ware LB, Matthay MA 2001 Alveolar fluid clearance is impaired in the majority of patients with acute lung injury and the acute respiratory distress syndrome. Am J Respir Crit Care Med 163:1376-1383

34. Meyuhas D, Nir S, Lichtenberg D 1996 Aggregation of phospholipid vesicles by water-soluble polymers. Biophys J 71:2602-2612

35. Lu JJ, Cheung WW, Yu LM, Policova Z, Li D, Hair ML, Neumann AW 2002 The effect of dextran to restore the activity of pulmonary surfactant inhibited by albumin. Respir Physiol Neurobiol 130:169-179 